organize a meeting on the subject in London last week, gathering representatives from universities, funders, journals and lobby groups to discuss how the problem could be tackled in the United Kingdom (see Nature http://doi.org/hmx; 2012). The meeting broke little new ground, but its organizers do, at least, deserve credit for trying.

A big part of the problem is the lack of perceived risk associated with misconduct. Some fraudulent researchers might be sociopaths who don't care about the rules, but many others simply believe that they can anticipate the outcome of a research project, and see no downside to fabricating the required results to save time, or tweaking results to achieve a stronger signal. Either way, stronger action and punishments are needed to discourage such misbehaviour. (Meanwhile, for colleagues considering blowing the whistle, the risks are glaringly huge witness the plight of scientists, such as cardiologist Peter Wilmshurst, who have raised questions and have faced the full force of Britain's ludicrous libel laws as a result.)

Could publications such as this one do more to deter cheats? Unfortunately, we are often in no position to flag up even proven cases of misconduct, and thereby highlight the risks that miscreants run with their careers. Yes, it is a journal's primary job to clean up the literature, but when papers are retracted owing to misconduct, the libel laws (again) often prevent our editors from saying so. We know that this leaves the affected communities frustrated and in the dark. It leaves us frustrated, too.

So, with journals unable to push towards greater integrity and universities often unwilling to do so, should funding agencies be leading the charge? It is, after all, their money that is wasted if misconduct does occur.

Funding agencies in the United States do sometimes investigate misconduct. Research funded by the National Institutes of Health and some other government agencies falls under the remit of the Office for
Research Integrity (ORI), which has the power to bar researchers from receiving future funding. However, as Nicholas Steneck, director of the research-ethics programme at the Michigan Institute for Clinical and Health Research in Ann Arbor, told the London meeting, this process probably misses most major misconduct. And the ORI can't initiate investigations: institutions must conduct their own inquiries first.

"Stronger
action and
punishments
are needed to
discourage
misbehaviour."

In the United Kingdom, there seems to be little appetite for launching an overarching ORI-type regulator. Certainly, the existing independent advisory group, the UK Research Integrity Office in Falmer, is clear that it has no desire to take on such a role. British funding councils - in collaboration with the country's universities - have chosen instead to produce a 'concordat' detailing good practice, to which institutions will be expected to sign up. This is laudable, but unlikely to strike fear into fraudsters and fabricators.

So, how can Britain highlight cases of misconduct and discourage it in future? Ultimately, the incentives probably need to come from on high, and the government could get the ball rolling by commissioning an anonymous survey on misconduct that UK researchers have witnessed and perpetrated. An official audit would offer a strong platform for others to build on - perhaps with a parliamentary inquiry and subsequent report on the damage done to UK science by misconduct, and an assessment of the options for tackling it and the investment needed. Funders and universities could then work together to establish common definitions of what counts as misconduct, and how it will be punished. And if a reform of the libel laws goes ahead, journals and other scientists would be able to do more to highlight and expose miscreants.

Sounds ambitious? If the solutions were easy, there wouldn't be a problem to discuss. But there is, so we must face it.

\section{Cap in hand}

\section{A word to the wise on getting that much-needed research funding.}

$\mathrm{W}$ ould you be willing to spend weekends on the yacht of a friendly billionaire in the name of science? Or insist to airport check-in staff that your life-saving research demands that you be upgraded from economy to business class? Perhaps you would be happy to see your face on a T-shirt? Or for folks you met on the Internet to traipse through your lab, taking photographs?

Welcome to the cold reality of science in a global recession. As the flow of public money slows across the world, academic researchers are increasingly turning to private funders and wealthy individualsturned-philanthropists to pay for their work. There is a strong tradition of such support already, of course, especially in the biomedical field. But as government cuts around the world begin to bite, more and more scientists will be looking for alternative sources of income.

So, in a short series of articles this week, Nature focuses on where that money is and how you can access it. Do not feel too proud to ask. Some of your competitors are doing it already.

In our News Features, we look at the two extremes of research paid for by private individuals - from the billionaires willing to set up entire laboratories and pay for the work done there for years, to the web-based begging bowls that can take just a few dollars each from thousands of different people.

On page 254, we talk to those at the top: the big spenders, the entrepreneurs - and those scientists who have benefited from their largesse. How did they do it? Partly by being in the right place at the right time, although it helps to know where the right places are. And it helps even

more to have something to say when you get there. As Thomas Pierson of the SETI Institute in Mountain View, California, says, "People give money to people." One secret seems to be to think big. "If I ask for $\$ 100,000$ and they say 'yes' right away, then I didn't ask for enough," one university fund-raiser tells us. "It's a common mistake."

At the other end of the scale are the crowd-funding websites, explored on page 252, where scientists can post details of their projects and ask many individuals to collectively cough up for them. From a low-cost robot for tackling oil spills to a project to map water quality along the Mississippi River, some researchers are already adept at tapping the potential of the masses. And although the target donors may be different, one key strategy remains the same: tell a good story. Sell yourself and sell your science.

Still, be wary of selling yourself short, warns a Comment piece on page 260. Patrick Aebischer, president of the École Polytechnique Fédérale de Lausanne in Switzerland, complains that too many donations to university research from charities and foundations come with a catch - they don't pay for the associated costs, such as salaries and utility bills. "Institutions with many privately funded projects are effectively 'punished' for their success," he writes. "To meet the higher research-infrastructure costs, universities may drain resources from education, or diminish 'expensive' disciplines such as physics, chemistry or engineering, in which philanthropic support is scarce." The solution, he says, is for institutions to identify the full cost of research activities and pass it on. "Private bodies should not hijack university resources. They should contribute a fair share of the expense."

The money is certainly out there. Just look at the billions poured into football teams. And if the pages of the glossy magazines can be

D NATURE.COM To comment online, click on Editorials at: go.nature.com/xhunqv believed, the luxury-goods market remains strong. The money must be spent on something, so why not science? And although those weekends on luxury yachts may be a tough way to make it happen, someone has to do it.. 